\title{
Serum Antibodies Protect against Intraperitoneal Challenge with Enterotoxigenic Escherichia coli
}

\author{
Xinghong Yang, ${ }^{1}$ Theresa Thornburg, ${ }^{1}$ Kathryn Holderness, ${ }^{1}$ Zhiyong Suo, ${ }^{2}$ Ling Cao, ${ }^{1}$ \\ Timothy Lim, ${ }^{1}$ Recep Avci, ${ }^{2}$ and David W. Pascual ${ }^{1}$ \\ ${ }^{1}$ Department of Immunology \& Infectious Diseases, Montana State University, Bozeman, MT 59717-3610, USA \\ ${ }^{2}$ Imaging and Chemical Analysis Laboratory, Department of Physics, Montana State University, Bozeman, MT 59717, USA
}

Correspondence should be addressed to Xinghong Yang, yangxh@montana.edu

Received 15 March 2011; Revised 27 April 2011; Accepted 17 June 2011

Academic Editor: Gad Frankel

Copyright ( 2011 Xinghong Yang et al. This is an open access article distributed under the Creative Commons Attribution License, which permits unrestricted use, distribution, and reproduction in any medium, provided the original work is properly cited.

\begin{abstract}
To assess whether anticolonization factor antigen I (CFA/I) fimbriae antibodies (Abs) from enterotoxigenic Escherichia coli (ETEC) can protect against various routes of challenge, BALB/c mice were immunized with a live attenuated Salmonella vaccine vector expressing CFA/I fimbriae. Vaccinated mice elicited elevated systemic IgG and mucosal IgA Abs, unlike mice immunized with the empty Salmonella vector. Mice were challenged with wild-type ETEC by the oral, intranasal (i.n.), and intraperitoneal (i.p.) routes. Naïve mice did not succumb to oral challenge, but did to i.n. challenge, as did immunized mice; however, vaccinated mice were protected against i.p. ETEC challenge. Two intramuscular (i.m.) immunizations with CFA/I fimbriae without adjuvant conferred $100 \%$ protection against i.p. ETEC challenge, while a single $30 \mu \mathrm{g}$ dose conferred $88 \%$ protection. Bactericidal assays showed that ETEC is highly sensitive to anti-CFA/I sera. These results suggest that parenteral immunization with purified CFA/I fimbriae can induce protective Abs and may represent an alternative method to elicit protective Abs for passive immunity to ETEC.
\end{abstract}

\section{Introduction}

Travelers' diarrhea still poses risk to inhabitants of endemic areas [1]. Traveling to such areas results in approximately $40 \%$ of travelers experiencing at least one episode of diarrhea [2], which accounts for 160 million new cases annually [3]. Among the causative agents, enterotoxigenic Escherichia coli (ETEC) is responsible for $\sim 76 \%$ of these cases [4]. ETEC also afflicts young children, resulting in the deaths of 300,000 500,000 children aged $<5$ years $[5,6]$. In the United States, ETEC is considered an emerging cause of foodborne disease [7]. ETEC is also a diarrheal disease in livestock, especially in piglets, and represents a significant economic burden $[8,9]$. Thus, an effective vaccine against ETEC is desirable given that there are currently no licensed vaccines for human ETEC [10].

The essential determinants of ETEC virulence are directly linked to the production of fimbrial or afimbrial colonization factor antigens (CFAs) and heat-stable and/or heat-labile toxins $[8,11,12]$. Previous studies have shown that CFA/I fimbriae are expressed on the cell surface of ETEC, facilitating its attachment to epithelial cells of the human small intestine, thus serving as a virulence factor [13]. Challenge studies in humans suggest that CFA/I fimbriae are protective antigens (Ags) [13-15]. Previous results from our laboratory have shown that a single dose of $S$. typhimurium-CFA/I vaccine is sufficient to elicit elevated secretory immunoglobulin A (SIgA) and systemic IgG antibody (Ab) responses to CFA/I fimbriae due to the induction of a dominant Th2-type response $[16,17]$.

ETEC is host specific [18], making the testing of ETEC vaccines difficult. Likewise, effective vaccines for livestock are lacking, which is in part attributed to host diversity: $\mathrm{K}^{2} 8^{+}$ETEC mostly infects swine $[9,19,20]$, and $\mathrm{K}^{+} 9^{+}$ mostly infects calves and lambs [21-23]. ETEC isolated from humans harbors CFAs and is the causative agent for human diarrhea disease [24-26]. Although suitable animal models for studying human ETEC are not readily available, previous studies have shown that neutralizing Abs induced to ETEC in mice can provide possible insight to vaccine 
efficacies [27, 28]. To circumvent host specificity, others have sought different routes of infection, including intranasal (i.n.), intraperitoneal (i.p.), and oral routes, to determine protection with experimental vaccines [27, 29-31]. Rabbits have also been used to assess protection, using the RITARD model $[32,33]$, and one such study shows the ability of mouse IgG mAbs against CFAs to confer protection [32]. In a similar vein, chicken yolk IgY Abs are able to passively protect using the RITARD model [33]. Thus, while local production of protective Abs would be ideal for protection against ETEC, immune Abs derived from milk [34], yolk [33], or mAbs [32] are possible alternatives to locally produced SIgA.

In this study, we questioned whether protective Abs induced to ETEC would be protective against different routes of challenge. We elected to use two formulas of the CFA/I subunit vaccines in this study: one is carried by the Salmonella vaccine vector $\mathrm{H} 683$, and the other formulation uses purified CFA/I fimbriae protein. A S. typhimuriumderived vaccine strain was used in this study because, although S. typhimurium and S. Typhi are both human pathogens, S. Typhi does not normally infect mice [35]. Other live vectors for carrying CFA/I fimbriae such as E. coli were excluded since our previous work had shown that the E. coli-based vaccine is not sufficiently immunogenic [36]. In contrast, heterologous gene expression by Salmonella had previously been shown to be highly immunogenic $[16,17]$, and this mucosal vaccine has the advantage of being needlefree and does not require cold-chain preservation. Moreover, efficacy by the purified CFA/I fimbriae was conducted.

I.n. ETEC challenge was proposed as an alternative means to infect mice [27]. However, mice orally immunized with Salmonella-CFA/I proved ineffective against nasal challenge but were protected against i.p. challenge, showing that the induced immune IgG Abs are protective against ETEC. Moreover, i.m. immunization with recombinant CFA/I fimbriae with or without adjuvant was also found to be neutralizing, suggesting that i.p. infection provides an alternative means to assess protective Abs elicited by fimbrial vaccines.

\section{Materials and Methods}

2.1. Bacterial Strains, Plasmids, and Media. The bacterial strains, plasmids, and their relevant characteristics are provided in Table 1. Strains containing plasmids were grown at $37^{\circ} \mathrm{C}$ in Lysogeny broth (LB; $10 \mathrm{~g}$ of tryptone, $10 \mathrm{~g}$ of $\mathrm{NaCl}$, and $5 \mathrm{~g}$ of yeast extract/L). Diaminopimelic acid (DAPA) $(50 \mu \mathrm{g} / \mathrm{mL})$ was used for E. coli $\mathrm{H} 681$ or S. typhimurium H683 culture, unless a plasmid containing asd gene was introduced. Wild-type (wt) ETEC strain H10407 is a human isolate commonly used in challenge experiments [37]. H10407 was selected due to its prototypical feature of ETEC, that is, it reproducibly elicits diarrhea in human volunteer studies [39]. Additionally, CFA/I fimbriae used in this study were originally cloned from this strain [36]. The wt ETEC B41 is a bovine pathogen [38]. To investigate whether the anti-CFA/I sera are able to neutralize the heterologous ETEC, strain B41 was selected since it produces K99 fimbriae.
Bacteria were cultured in $\mathrm{LB}$ and stored at $-80^{\circ} \mathrm{C}$ in $\mathrm{LB}$ plus $20 \%$ glycerol.

Previous work has shown that the $c f a / I$ operon is expressed constitutively in plasmid pJGX15C-asd [36], and its regulation is under the control of a tetracycline promoter (PtetA). To enhance $c f a / I$ expression, the macrophageinducible promoter from $S$. typhimurium $\mathrm{H} 683$ phoP gene (PphoP) was selected [40] to enable $c f a / I$ expression. The PphoP from plasmid pV4 was digested with NheI and SacI restriction enzymes, as previously done, to enhance plague F1- and V-Ags [41], and this DNA segment was subsequently purified from agarose gel and inserted to pJGX15C-asd between NheI and SacI sites, replacing PtetA. This new plasmid is referred to as pC1 (Table 1). Expression of CFA/I fimbriae was confirmed by Western blot analysis, as previously described [41].

2.2. CFA/I Fimbrial Protein Isolation and Purification. CFA/I fimbrial protein isolation and purification from E. coli $\mathrm{H} 695$ were performed, as previously described $[16,42]$. Since CFA/I fimbriae are produced in E. coli, contaminating LPS was removed using Detoxi-Gel Endotoxin Removal Gel (Pierce, Rockford, ILL). CFA/I fimbriae were allowed to incubate on the resin for 3-4 hours (hrs) to increase contact time with the polymyxin B and applied to the resin multiple times (typically 2-4 times) until the endotoxin levels were below $6.4 \mathrm{ng} / \mathrm{mL}$ in sterile phosphate buffered saline (sPBS). The limulus amebocyte lysate (LAL) test (Associates of Cape Cod, Inc., East Falmouth, Mass) was used according to manufacturer directions to verify endotoxin levels.

2.3. Immunization and Challenge of Mice. Female BALB/c mice at 7 to $9 \mathrm{wk}$ of age were obtained from Frederick Cancer Research Facility (National Cancer Institute, Frederick, Md) and used throughout the study, as previously described [16]. All mice were maintained in laminar flow racks under conditions of $12 \mathrm{hr}$ of light and $12 \mathrm{hr}$ of darkness and provided with food and water ad libitum. All animal experiments, including immunization and challenge, were performed at the Montana State University Animal Resource Center. All animal care and procedures were in accordance with institutional policies for animal health and well-being.

S. typhimurium H683-pC1, control S. typhimurium H647, and wt ETEC strains H10407 and B41 were grown overnight in $\mathrm{LB}$ at $37^{\circ} \mathrm{C}$. $\mathrm{H} 683-\mathrm{pC} 1$ and $\mathrm{H} 647$ cells were pelleted, washed twice in sPBS, and diluted to $5 \times$ $10^{9}$ cells $/ 200 \mu \mathrm{L}$ in sPBS. The actual viable inoculum, colonyforming unit (CFU), was confirmed by serial dilution test on LB agar plate. Mice (5 per group) were orally immunized twice with $200 \mu \mathrm{L}$ of the bacterial suspension on days 0 and 28 . The experiment was repeated twice.

For oral challenges, wt ETEC H10407 was diluted in sPBS in which $200 \mu \mathrm{L}$ of bacterial suspension contained $5 \times$ $10^{9}$ or $5 \times 10^{8}$ CFUs of bacteria and was used to orally gavage mice previously treated with a $100 \mu \mathrm{L} \mathrm{50 \%} \mathrm{saturated}$ sodium bicarbonate solution $30 \mathrm{~min}$ prior to challenge, as previously described [17]. For i.n. challenges, mice were lightly anesthetized by inhalational isoflurane (Halocarbon 
TABLE 1: Bacterial strains, plasmids, and their characteristics.

\begin{tabular}{|c|c|c|}
\hline Bacterial strains & Characteristics & Sources or references \\
\hline E. coli $\mathrm{H} 681$ & $a s d^{-}$ & {$[31]$} \\
\hline E. coli $\mathrm{H} 695$ & $c f a / I^{+}$ & {$[16]$} \\
\hline enterotoxigenic E. coli $\mathrm{H} 10407$ & wt, serotype $078: \mathrm{K} 80: \mathrm{H} 11$ & [37] \\
\hline enterotoxigenic E. coli $\mathrm{B} 41$ & wt, serotype O101: $\mathrm{K}^{-}$ & {$[38]$} \\
\hline S. typhimurium $\mathrm{H} 683$ & asd ${ }^{-} a r o A^{-}$ & {$[31]$} \\
\hline S. typhimurium $\mathrm{H} 647$ & $a s d^{+}$ & {$[31]$} \\
\hline \multicolumn{3}{|l|}{ Plasmids } \\
\hline pJGX15C-asd & $c f a / I^{+}$ & {$[36]$} \\
\hline $\mathrm{pC1}$ & derived from pJGX15C-asd & This study \\
\hline
\end{tabular}

Products Corp, River Edge, NJ) and subsequently infected with wt ETEC H10407 diluted in sPBS containing $5 \times 10^{9}$ or $5 \times 10^{8}$ CFUs of bacteria in $50 \mu \mathrm{L}$ applied dropwise to the nares using $25 \mu \mathrm{L} /$ nostril, as previously described [27]. For i.p. challenges, wt ETEC H10407 diluted in $200 \mu \mathrm{L}$ sPBS containing $5 \times 10^{7}$ CFUs was then subsequently injected. Challenge was performed at 7 -wk postprimary immunization, and the challenge doses were confirmed by plating H10407 on LB agar after serial dilutions of the inoculum.

For the CFA/I fimbriae immunization studies, mice were immunized with purified, low-endotoxin CFA/I fimbriae in sPBS $(1.2-3.0 \mu \mathrm{g} / \mu \mathrm{L})$ by intramuscular (i.m.) injection. Two doses of $60 \mu \mathrm{g}, 100 \mu \mathrm{g}$, or $150 \mu \mathrm{g}$ CFA/I fimbriae at 2-wk intervals were injected into $\mathrm{BALB} / \mathrm{c}$ mice tibialis anterior muscles. As a negative control, additional mice were similarly immunized with sPBS. The volume used for injection was $25 \mu \mathrm{L}$ per leg. At the indicated time intervals, serum and fecal samples were collected to assess serum IgG and IgG subclass and fecal IgA endpoint titers. In each experiment, 3-4 mice per group were used, and the experiment was done twice for a total of 7 mice per group.

For some experiments, mice were i.m. immunized with a single 10 or $30 \mu \mathrm{g}$ dose of purified, low-endotoxin CFA/I fimbriae with or without the coadministration of the mucosal adjuvant, cholera toxin (CT) (List Biological Laboratories, Campbell, Calif). At 0, 2, and 3 wks after immunization, serum IgG and mucosal IgA anti-CFA/I endpoint titers were measured by ELISA. Challenge with wt ETEC was performed at 4 -wk postprimary immunization. In each experiment, 4 mice per group were used, and the experiment was done twice for a total of 8 mice per group.

For mouse colonization studies, mice ( 5 per group) were immunized with $10 \mu \mathrm{g}$ detoxed CFA/I fimbriae plus $2.5 \mu \mathrm{g}$ $\mathrm{CT}$, or given PBS only. At $3 \mathrm{wks}$ after immunization, mice were i.p. challenged with $5 \times 10^{7} \mathrm{CFUs}$ of wt ETEC H10407. At 4,8 , and $16 \mathrm{hr}$ after challenge, spleen, liver, kidneys, and lungs from individual mice were mechanically homogenized in sterile Milli-Q water. Samples were serially diluted on LB agar for overnight incubation at $37^{\circ} \mathrm{C}$, and the bacterial CFUs were enumerated.

2.4. Endpoint $A b$ Titer Determinations. To determine the induced serum and mucosal Abs to CFA/I fimbriae, endpoint titers were measured, as previously described by CFA/I fimbriae-specific ELISA [16, 17]. Specific reactivities to CFA/I fimbriae were determined using horseradish peroxidase conjugates of detecting Abs: goat antimouse IgG, IgA, IgG1, IgG2a, IgG2b, or IgG3 Abs (Southern Biotechnology Associates, Birmingham, Ala) in combination with substrate, 2,2' -azinobis (3-ethylbenzthiazoline-6-sulfonic acid) diammonium (Moss Inc., Pasadena, CA). Absorbances were read at $415 \mathrm{~nm}$ on an ELx808 microplate reader (Bio-Tek Instruments, Winooski, Vt). Endpoint titers were expressed as the reciprocal of the last sample dilution giving an absorbance of 0.1 optical density (OD) unit at $415 \mathrm{~nm}$ above the $\mathrm{OD}_{415}$ of negative controls after 1-hr incubation at room temperature.

2.5. Bactericidal Test. Sera collected from the CFA/I fimbriae-immunized mice and the sPBS-dosed mice were diluted with sPBS [43] by 2-, 4-, and 8-fold. An equal volume of wt ETEC H10407 and B41 cells harvested from logarithmic phase with a density of $500-1,000 \mathrm{CFUs} / \mu \mathrm{L}$ was added to the nondiluted and diluted sera. Thus, the serum was finally diluted to 2-, 4-, 8-, and 16-fold in the bacteria and serum mixtures. Samples were mixed evenly and incubated at $37^{\circ} \mathrm{C}$ for $0,20,40$, and $60 \mathrm{~min}$. Subsequently, samples were removed after thorough mixing and colony counts made at each time point, as previously described [41]. This experiment was done three times.

2.6. Statistical Analysis. The Student's $t$-test was used to evaluate the differences between experimental parameters in each experiment, and the $P$ values $<0.05$ are indicated. The Kaplan-Meier method (GraphPad Prism, GraphPad Software, Inc., La Jolla, CA) was applied to obtain the mouse survival fractions following infection with a lethal dose of wt ETEC strain H10407. Using the Mantel-Haenszel log rank test, the $P$ values for statistical differences between vaccinated and naïve mice were discerned at the $95 \%$ confidence interval.

\section{Results}

3.1. Oral Immunization with S. typhimurium H683-pC1 Vaccine Stimulates Elevated Serum and Mucosal Anti-CFA/I Fimbriae Abs. To evaluate the ability of S. typhimurium 
H683-pC1 to elicit anti-CFA/I titers, two groups of BALB/c mice were orally immunized with $5 \times 10^{9}$ CFUs of H683pC1 and H647, respectively. Mice were boosted 4 wks later with the same dose, and anti-CFA/I fimbriae endpoint titers were determined for both serum IgG and copro-IgA Abs. At wk 6 postprimary immunization, serum IgG anti-CFA/I fimbriae titers were $2^{16.8}$, and copro-IgA anti-CFA/I titers were $2^{8.8}$ (Figure 3(a)), suggesting that H683-pC1 was highly immunogenic. Minimal to no anti-CFA/I fimbriae titers were observed in the empty Salmonella vector H647-immunized mice, similar to that previously described $[16,36]$. At wk 6, serum IgG subclass responses to CFA/I fimbriae were also measured. The IgG1 titers were similar to IgG2a, but significantly greater than $\operatorname{IgG} 2 \mathrm{~b}(P<0.05)$ and $\operatorname{IgG} 3(P<$ $0.001) \mathrm{Ab}$ titers, and the IgG2a titers were significantly greater than IgG3 Ab titers $(P<0.01)$ (Figure $3(\mathrm{~b}))$. These results indicate that IgG1, IgG2a, and IgG2b subclasses dominated the serum anti-CFA/I IgG response, implicating that a mixed Th cell response was induced by H683-pC1.

3.2. Oral Immunization with H683-pC1 Protects against I.P. Challenge with wt ETEC. To determine whether routes of challenge influence susceptibility to ETEC infection, H683-pC1- and H647-immunized mice (Figure 3(a)) were challenged via oral (Figure 3(c)), i.n. (Figure 3(d)), or i.p. (Figure 3(e)) routes with wt ETEC strain H10407. All mice survived either oral challenge dose $\left(5 \times 10^{8}\right.$ CFUs and $5 \times 10^{9}$ CFUs) (Figure 3(c)). All mice survived nasal challenge with the low dose of $5 \times 10^{8}$ CFUs (Figure $3(\mathrm{~d})$ ), but only $50 \%$ of the mice from H683-pC1- and H647-immunized groups survived the high dose of $5 \times 10^{9}$ CFUs. Only one dose of $5 \times$ $10^{7}$ CFUs was tested for i.p. challenge, and $80 \%$ of the H683pC1-immunized mice were protected $(P<0.05)$, unlike the H647-immunized mice that succumbed to challenge (Figure 3(e)). These results show mice are not susceptible to the oral challenge route by the human ETEC strain H10407. Moreover, nasal challenge also proved insufficient against the low dose $\left(5 \times 10^{8} \mathrm{CFUs}\right)$ challenge, while a high-dose $\left(5 \times 10^{9}\right.$ CFUs $)$ proved to be lethal since $50 \%$ of H683pC1- and H647-vaccinated mice succumbed to infection. However, H683-pC1-vaccinated mice were protected against i.p. challenge, and control mice (H647-vaccinated) were sensitive to the i.p. route of challenge by human ETEC.

\subsection{Purified CFA/I Fimbriae Effectively Stimulate Elevated} $A b$ Reponses following I.M. Immunization. Previous studies have shown that anti-CFA/I fimbriae Abs are protective against ETEC infection $[14,15,34]$. While Abs induced subsequent to oral immunization with the Salmonella-based vaccine protected mice from ETEC challenge (Figure 3(e)), we questioned whether immunizing mice with the CFA/I fimbriae alone would be sufficient to confer protection. $\mathrm{BALB} / \mathrm{c}$ mice were i.m. immunized with sPBS-buffered detoxed CFA/I fimbriae at doses of $60 \mu \mathrm{g}, 100 \mu \mathrm{g}$, or $150 \mu \mathrm{g}$, with sPBS as a control. They were subsequently boosted 2 wks later with the same doses. The CFA/I fimbriae induced robust immune responses (Figures $1(\mathrm{a})-1(\mathrm{c})$ ), and sPBSdosed mice showed no anti-CFA/I Ab titers (Figure 1(d)).
Regardless of immunization dose, copro-IgA titers amongst the three immunization groups did not differ significantly and attained as much as $2^{7.1}$. Serum IgG titers at wk 3 were greatly elevated between $2^{16}$ and $2^{17.4}$. Although no statistical differences were obtained in IgG titers between the groups immunized with 60 and $100 \mu \mathrm{g}$ of CFA/I fimbriae, these titers were significantly greater than the group immunized with $150 \mu \mathrm{g}$ dose (Figure 1(a) versus $1(\mathrm{c}), P<0.05$; Figure 1(b) versus Figure $1(\mathrm{c}), P<0.001)$. These results suggest that increasing the dose of CFA/I fimbriae does not necessarily enhance the humoral immune response. Collectively, these results indicate that as little as $60 \mu \mathrm{g}$ CFA/I fimbriae is sufficient for eliciting elevated serum IgG and mucosal IgA anti-CFA/I titers.

Sera from the $60 \mu \mathrm{g}, 100 \mu \mathrm{g}$ and $150 \mu \mathrm{g}$ CFA/I fimbriaeimmunized mice at 3 -wk postprimary immunization were further analyzed for IgG subclass responses. For all tested doses, the IgG1 titers were significantly greater than IgG2a, IgG2b, and IgG3 titers, while no statistical differences were found among IgG2a, IgG2b, and IgG3 titers (Figures 1(a)$1(\mathrm{c}))$. This result shows that the CFA/I fimbrial immunization favors an IgG1 $\mathrm{Ab}$ response that differs from live vaccine H683-pC1 immunization, which sustains a balanced immune response between IgG1 and IgG2a Abs (Figure 3(b)).

3.4. Immunization with CFA/I Fimbriae Protects Mice from Wt ETEC Challenge. To evaluate whether the CFA/I fimbriaeimmunized mice would protect against i.p. ETEC challenge, the above-immunized BALB/c mice (Figure 1) were i.p. challenged with $5 \times 10^{7}$ CFUs of wt ETEC H10407. The mice immunized with $60 \mu \mathrm{g}$ CFA/I fimbriae showed $100 \%$ efficacy $(7 / 7)$, while $14.3 \%$ of the sPBS-dosed mice survived $(1 / 7)(P<0.05)$ (Figure $1(\mathrm{e}))$. Thus, the detoxed subunit vaccine, CFA/I fimbriae, stimulated protective immunity. However, mice were immunized with $100 \mu \mathrm{g}$ and $150 \mu \mathrm{g}$ CFA/I fimbriae, and the survival rates diminished to $71.4 \%$ $(5 / 7)$ and $42.9 \%(3 / 7)$, respectively (Figure $1(\mathrm{e})$ ). This outcome shows that by increasing the CFA/I immunization dose, the protective efficacy diminishes. Given these findings, it may be possible to lower the dose of CFA/I fimbriae while maintaining protective efficacy.

3.5. Determination of the Minimal Dose of CFA/I Fimbriae to Elicit Protective Immunity. To determine the minimal dose that can achieve protection against i.p. ETEC challenge in BALB/c mice, two doses of detoxed CFA/I fimbriae were tested: 30 and $10 \mu \mathrm{g}$ per mouse. As naïve control, an additional group of mice was given sPBS. In addition, three more groups were given the same doses, but coadministered with $2.5 \mu \mathrm{g}$ CT. CT is a powerful adjuvant that induces immune responses to coadministered Ags [44]. CT was selected as an adjuvant because of its Th2 cell bias [45], which favors heightened humoral immune responses particularly beneficial for clearing extracellular pathogens [46], such as ETEC [47]. After i.m. immunization, individual copro-IgA and serum IgG endpoint titers were determined at 0,2 , and 3 wks after immunization (Figures 2(a)-2(c)). Elevated 


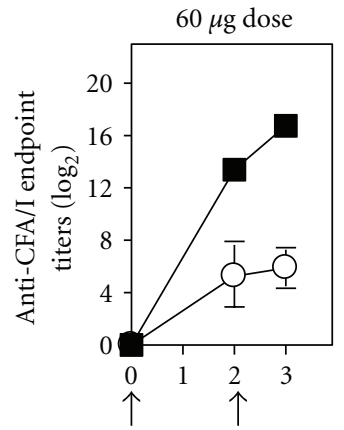

Time (wks)

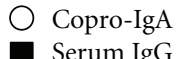

(a)

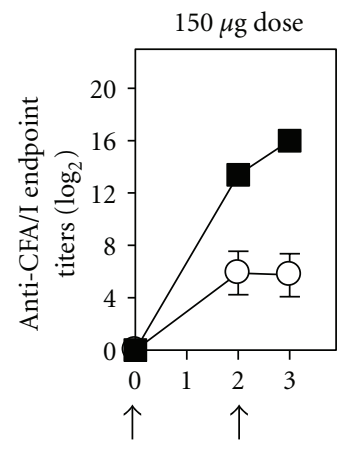

Time (wks)

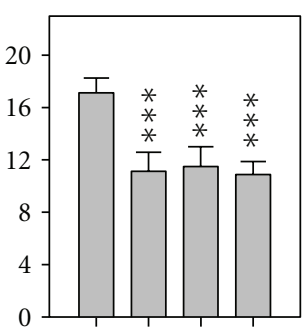

G1 G2a G2b G3

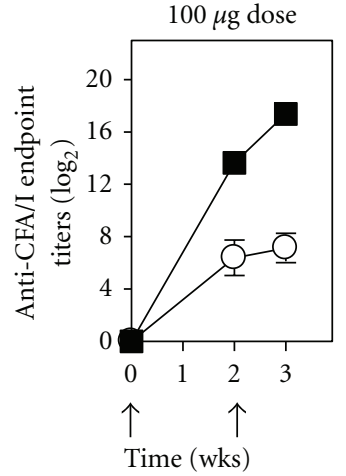

Copro-IgA

Serum IgG

(b)

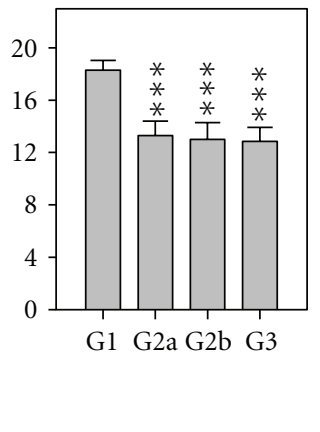

Copro-IgA

Serum IgG
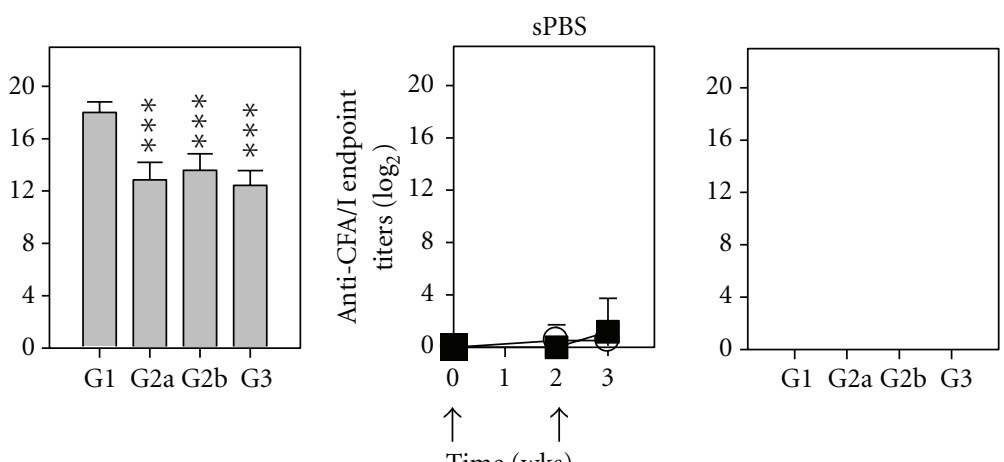

Time (wks)

Copro-IgA

Serum IgG

(c)

(d)

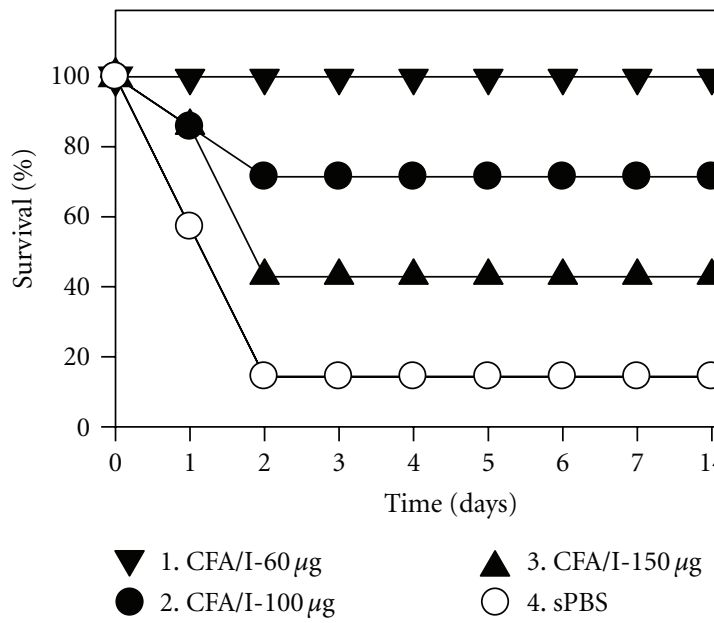

(e)

FIGURE 1: Evaluation of the protective immunity of the detoxed CFA/I fimbriae. (a)-(d) Endpoint Ab titers were induced to detoxed CFA/I fimbriae. BALB/c mice (7/group) were i.m. immunized with (a) 60, (b) 100, (c) 150, or (d) $0 \mu \mathrm{g}$ CFA/I fimbriae on days 0 and 14 . Serum IgG and mucosal IgA anti-CFA/I fimbriae endpoint Ab titers were measured at 0,2 , and 3 -wk postprimary immunization. IgG subclass responses were determined at wk 3 , and ${ }^{*} P<0.05,{ }^{* *} P<0.01$, and ${ }^{* * *} P<0.001$ versus IgG1 titers. (e) Assessment of the protective efficacy against i.p. ETEC challenge was determined. CFA/I fimbriae-immunized mice (a)-(c) and sPBS-dosed mice (d) were i.p. challenged with $5 \times 10^{7}$ CFUs of wt ETEC H10407 at 4-wk postprimary immunization. Mouse survival rates were observed for 14 days. The survival rates of $60 \mu \mathrm{g}$, $100 \mu \mathrm{g}$, and $150 \mu \mathrm{g}$ CFA/I fimbriae-immunized mice were $100 \%$ (7/7), 71.4\% (5/7), and 42.9\% (3/7), respectively, versus $14.3 \%$ (1/7) for sPBS-dosed mice. Survival fractions obtained from vaccinated mice were compared to sPBS-dosed mice, and significance was determined: $* P<0.05$. 

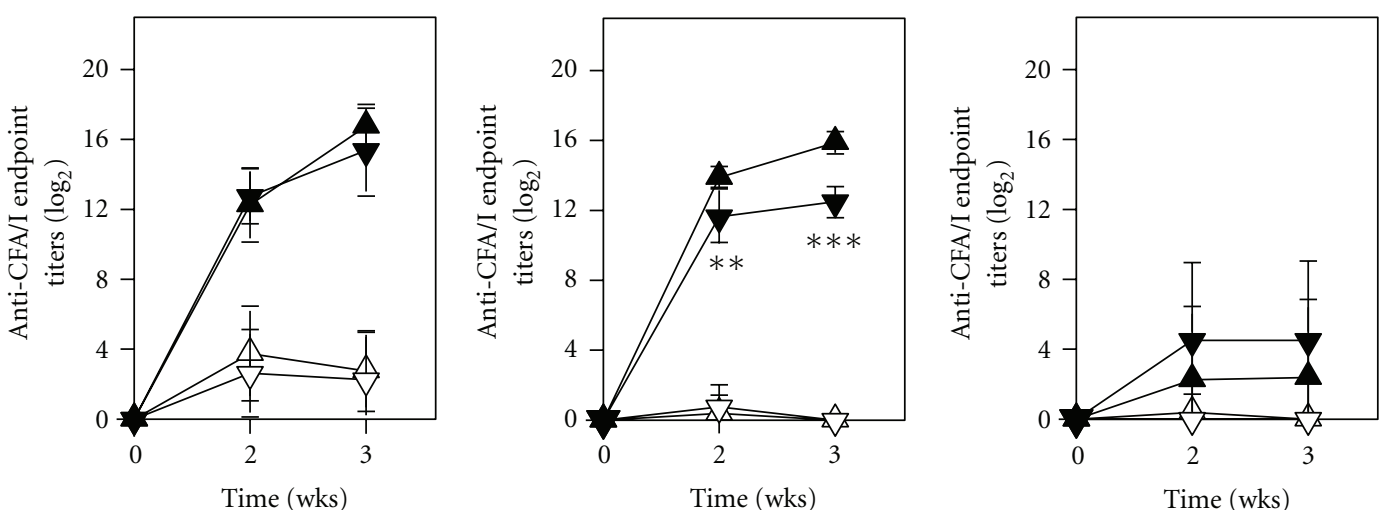

\begin{tabular}{|c|c|c|}
\hline & CFA/I & CT \\
\hline Copro-IgA $\triangle$ & 30 & 2.5 \\
\hline Serum-IgG $\boldsymbol{\Delta}$ & 30 & 2.5 \\
\hline Copro-IgA $\nabla$ & 30 & 0 \\
\hline Serum-IgG & 30 & 0 \\
\hline
\end{tabular}

(a)

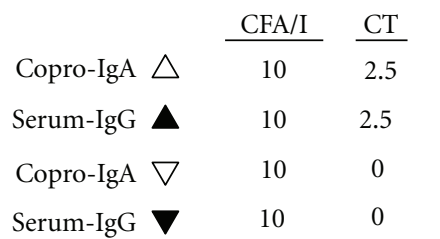

(b)

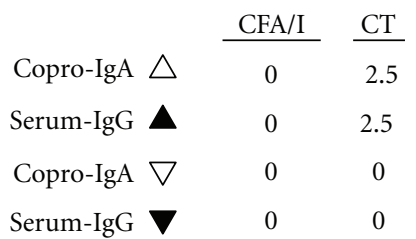

(c)

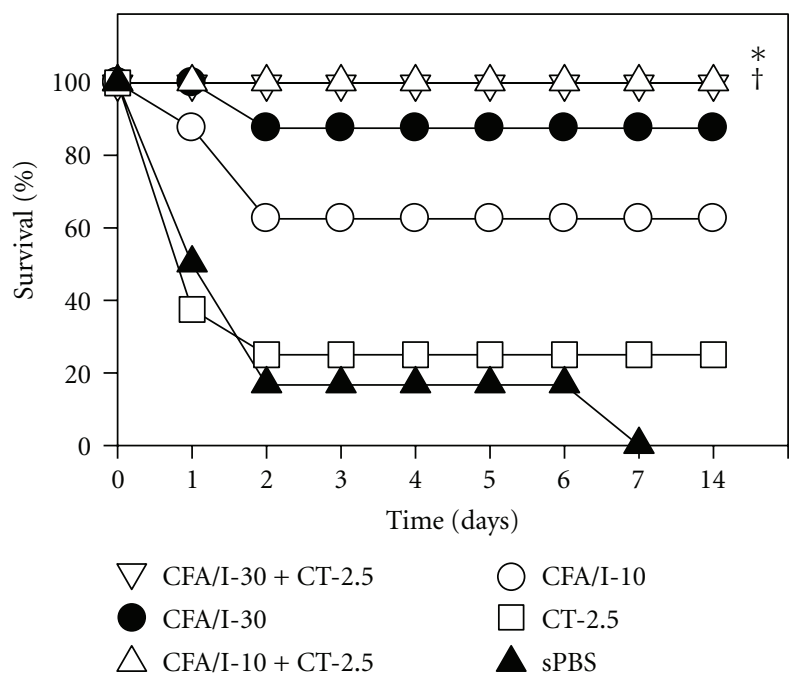

(d)

FIGURE 2: Evaluation of protective immunity induced by a low dose of CFA/I fimbriae. BALB/c mice (6-8/group) were i.m. immunized with (a) 30, (b) 10, and (c) $0 \mu \mathrm{g}$ detoxed CFA/I fimbriae with or without CT on day 0. (a, b) Elevated serum IgG and mucosal IgA anti-CFA/I $\mathrm{Ab}$ fimbriae responses were induced by $2 \mathrm{wks}$ after immunization (c), but not by control mice. Depicted is the mean \pm SD as $* * P<0.01$ and ${ }^{* * *} P<0.001$ versus $10 \mu \mathrm{g}$ CFA/I fimbriae-immunized mice. (d) Assessment of the protective efficacy by the low-dose CFA/I fimbriae-

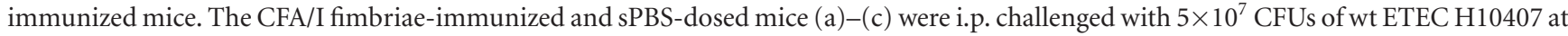
4 wks after immunization. Mouse survival rates were determined for 14 days. Both $30 \mu \mathrm{g}$ CFA/I $+2.5 \mu \mathrm{g}$ CT-immunized mice and $10 \mu \mathrm{g}$ CFA/I $+2.5 \mu \mathrm{g}$ CT-immunized mice survived (8/8); the survival rates for $30 \mu \mathrm{g}$ CFA/I- and $10 \mu \mathrm{g}$ CFA/I-immunized mice were $87.5 \%(7 / 8)$ and $62.5 \%$ (5/8), respectively; the $2.5 \mu \mathrm{g}$ CT-immunized mice showed $25 \%(2 / 8)$ survival; and the sPBS-dosed mice all succumbed to challenge (0/6). Survival fractions obtained from $30 \mu \mathrm{g}$ CFA/I $+2.5 \mu \mathrm{g}$ CT-immunized mice and $10 \mu \mathrm{g}$ CFA/I $+2.5 \mu \mathrm{g}$ CT-immunized mice were compared to sPBS-dosed mice and were determined, ${ }^{*} P<0.05$ and ${ }^{\dagger} P<0.05$, respectively.

serum IgG anti-CFA/I titers were obtained for both 10 and $30 \mu \mathrm{g}$ CFA/I fimbriae-dosed mice (Figures 2(a) and 2(b)), while the sPBS-dosed mice displayed only background titers (Figure 2(c)). Generally, the immune responses elicited by the $30 \mu \mathrm{g}$ CFA/I fimbriae were significantly greater than $10 \mu \mathrm{g}$ CFA/I fimbriae for mucosal IgA; without CT, the titers of
$30 \mu \mathrm{g}$ were compared with $10 \mu \mathrm{g}$ CFA/I fimbriae: $2^{2.3}$ versus $2^{0.0}$ at wk $3(P<0.05)$; with $C$ T, $2^{3.8}$ versus $2^{0.4}$ at wk $2(P<0.01)$ and $2^{2.8}$ versus $2^{0.0}$ at wk $3(P<0.01)$; and $\operatorname{IgG}$, without CT, the titers of $30 \mu \mathrm{g}$ were compared to $10 \mu \mathrm{g}$ CFA/I fimbriae: $2^{15.4}$ versus $2^{12.5}$ at wk $3(P<0.05)$; with $C T$, there was no significant difference. These results 


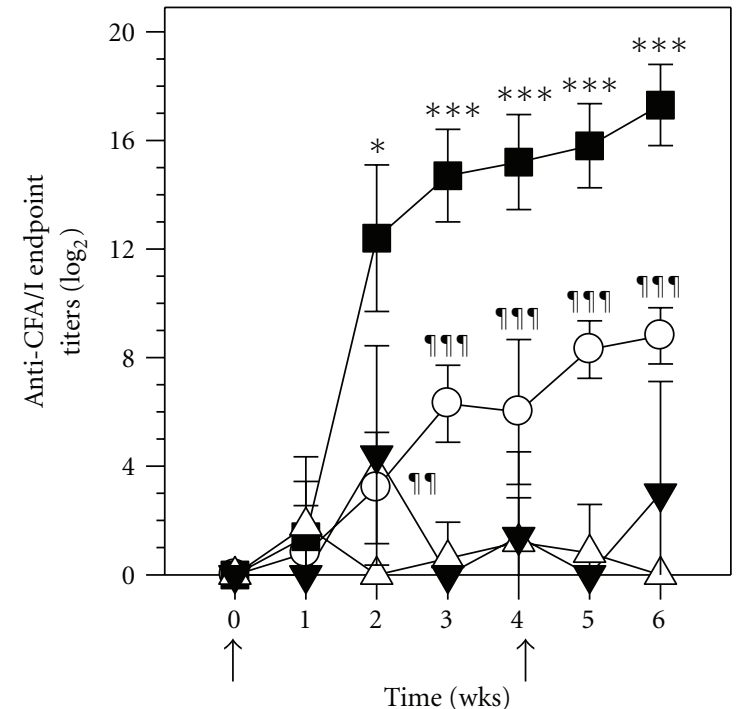

Time (wks)

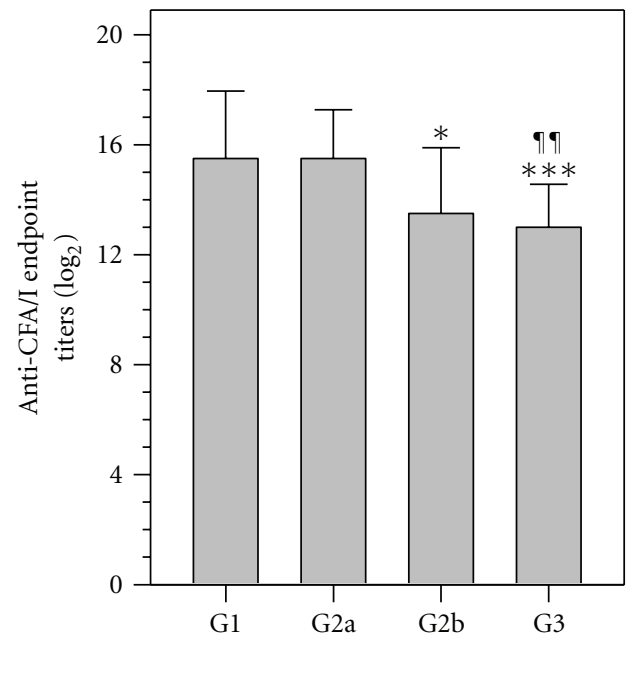
H683-pC1-IgA
H683-pC1-IgG
$\triangle$ H647-IgA
$\nabla$ H647-IgG

(a)

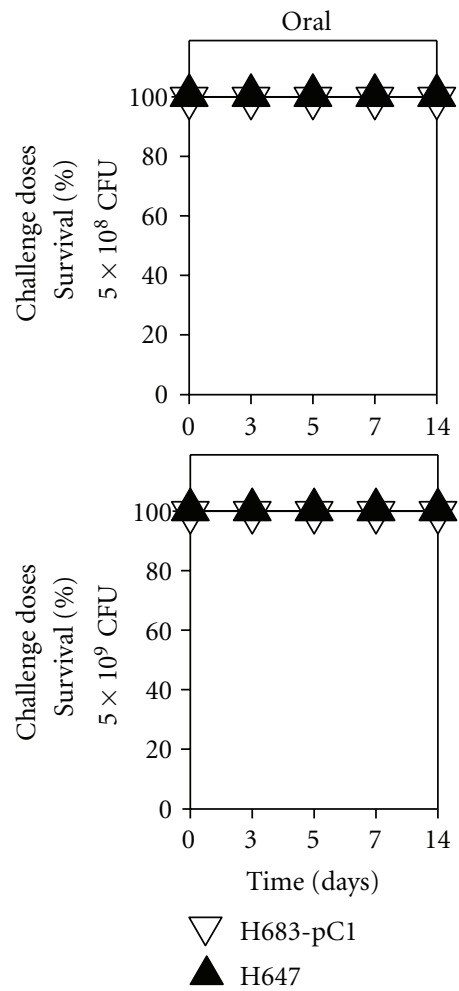

(c)
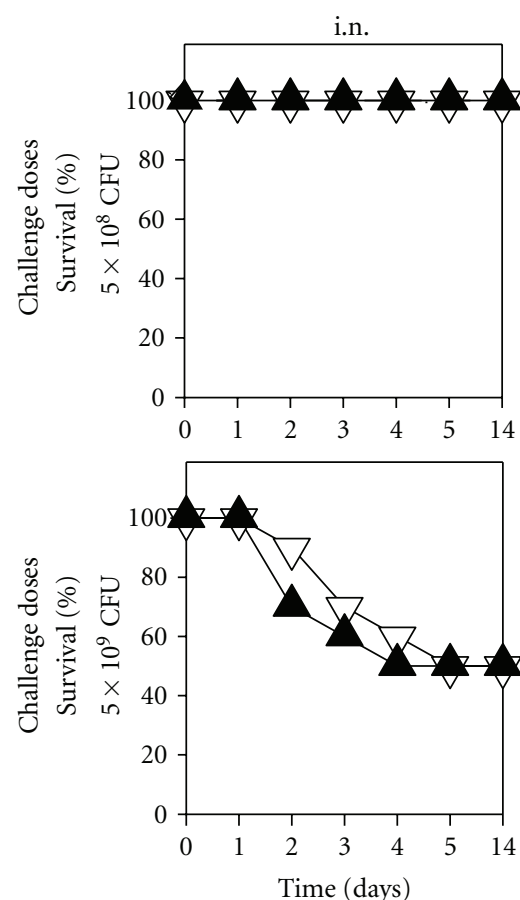

$\nabla$ H683-pC1

A $\mathrm{H} 647$

(d)

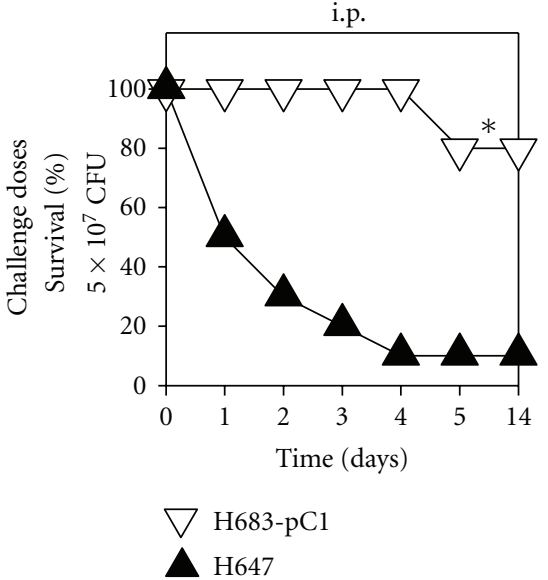

(e)

FIGURE 3: Salmonella vaccine H683-pC1 stimulates elevated anti-CFA/I fimbriae Ab titers and protects against i.p. ETEC challenge. (a) $\mathrm{BALB} / \mathrm{c}$ mice (5/group) were orally immunized twice on days 0 and 28 with $5 \times 10^{9}$ CFUs of S. typhimurium H683-pC1 and H647, respectively. Elevated serum IgG and mucosal IgA anti-CFA/I fimbriae Ab responses were induced. Depicted are the mean \pm SEM from two independent experiments. (b) At wk 6, serum IgG subclass analysis was performed, and statistical differences in the endpoint Ab titers were determined. ${ }^{*} P<0.05$, ${ }^{* *} P<0.01$, ${ }^{* *} P<0.001$ versus IgG1; ${ }^{\top \uparrow} P<0.01$ versus IgG2a. (c) $-(\mathrm{e})$ Comparison of different routes of challenges with wt ETEC H10407 among CFA/I fimbriae-immunized BALB/c mice. At 6-wk postprimary immunization, mice were challenged with wt ETEC H10407 (c) orally with $5 \times 10^{8}$ or $5 \times 10^{9}$ CFUs, (d) i.n. with $5 \times 10^{8}$ or $5 \times 10^{9}$ CFUs, or (e) i.p. with $5 \times 10^{7}$ CFUs. Mice survival was monitored for two wks. Results are from two independent experiments; survival fractions obtained from vaccinated mice were compared to H647-immunized mice, and significance was determined; ${ }^{*} P<0.05$. 


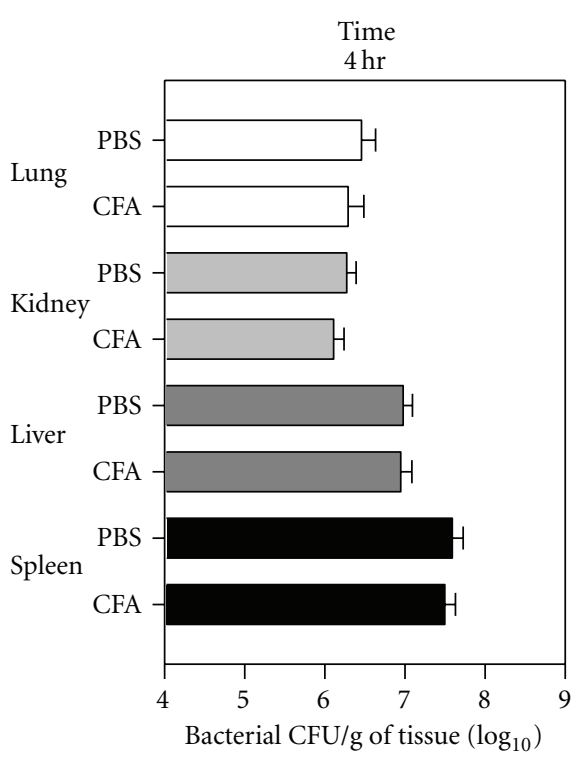

(a)

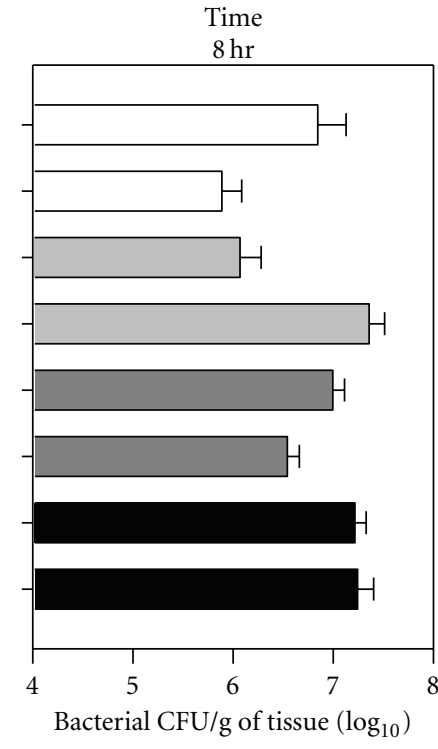

(b)

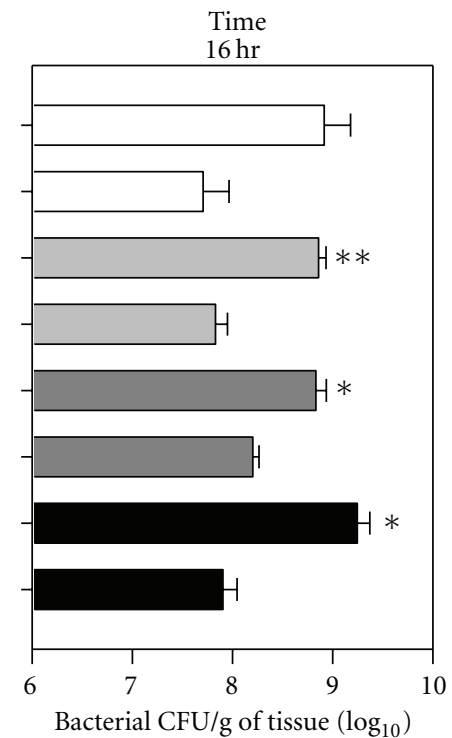

(c)

FIGURE 4: ETEC colonization in CFA/I fimbriae-immunized mice. Determination of ETEC colonization in mouse spleen, liver, lungs, and kidneys subsequent to ETEC challenge at (a) 4, (b) 8 , and (c) $16 \mathrm{hr}$ by CFA/I fimbriae-immunized $(10 \mu \mathrm{g}$ CFA/I fimbriae $+2.5 \mu \mathrm{g}$ CT) or PBS-dosed mice. Depicted is the mean \pm SD for differences in bacterial CFUs between CFA/I-dosed and sPBS-dosed mice; ${ }^{*} P<0.05$ and $* * P<0.01$.

indicate that unlike the $30 \mu \mathrm{g}$ CFA/I fimbrial dose, $10 \mu \mathrm{g}$ CFA/I fimbriae alone is insufficient to confer protection unless coadministered with CT adjuvant.

From the Ab titer measurements, the impact of CT adjuvant was not apparent when combined with the $30 \mu \mathrm{g}$ CFA/I fimbrial dose, since with or without CT, no significant differences were observed in serum IgG and mucosal IgA Ab titers (Figure 2(a)). However, the impact of CT adjuvant was evident in the CFA/I fimbrial dose of $10 \mu \mathrm{g}$ since significantly elevated IgG titers were achieved upon CT coadministration: $2^{13.9}$ versus $2^{11.6}$ at wk $2(P<0.01)$ and $2^{15.9}$ versus $2^{12.5}$ at wk $3(P<0.001)$ (Figure $2(\mathrm{~b}))$. This finding suggests that $10 \mu \mathrm{g}$ of CFA/I fimbriae requires adjuvant to induce elevated $\mathrm{Ab}$ titers.

To test whether the single low dose of CFA/I fimbriae was sufficient to confer protection, the above-immunized $\mathrm{BALB} / \mathrm{c}$ mice (Figures 2(a)-2(c)) were challenged i.p. with $5 \times 10^{7}$ CFUs of wt ETEC H10407. Of the mice immunized with 10 and $30 \mu \mathrm{g}$ CFA/I fimbriae coadministered with CT, the survival rates were $100 \%(8 / 8$ and $8 / 8)$ for both groups, but the survival rates for mice immunized with 30 and $10 \mu \mathrm{g}$ CFA/I fimbriae without CT were $87.5 \%(7 / 8)$ and $62.5 \%(5 / 8)$, respectively (Figure $2(\mathrm{~d})$ ). The survival rates for mice given CT or sPBS were only $25 \%(2 / 8)$ and $0 \%$ $(0 / 6)$, respectively (Figure $2(\mathrm{~d})$ ). Importantly, the survival rates for the two groups immunized with either dose of CFA/I fimbriae in combination with CT were significantly greater than that of the sPBS-dosed group $(P<0.05)$ (Figure $2(\mathrm{~d}))$. This shows that a single low dose of CFA/I fimbriae with adjuvant can achieve full protection. In the absence of adjuvant, immunization with $30 \mu \mathrm{g}$ CFA/I fimbriae achieved a protective effect very close to full protection (Figure 2(d)); nonetheless, $60 \mu \mathrm{g}$ CFA/I fimbriae alone could achieve 100\% protection (Figure 1(e)).

3.6. ETEC Colonization following CFA/I Fimbrial Immunization. Since recombinant CFA/I fimbriae conferred full protection to mice, we questioned how much ETEC colonized the various tissues in the protected mice. Groups of BALB/c mice were i.m. immunized with $10 \mu \mathrm{g}$ detoxed CFA/I fimbriae plus $2.5 \mu \mathrm{g}$ CT or with PBS alone. At 3 wks after immunization, mice were i.p. challenged with $5 \times 10^{7}$ CFUs of wt ETEC H10407. Since naïve mice could succumb to ETEC challenge by $24 \mathrm{hr}$ after challenge (Figures 3(e) and 3(d)), bacterial CFU levels were measured at 4, 8 , and $16 \mathrm{hr}$ after challenge for spleen, liver, kidneys, and lungs. The results showed no significant differences in colonization between CFA/I- and sPBS-immunized mice at 4 and $8 \mathrm{hr}$ after challenge in spleen, liver, kidneys, and lungs (Figures $4(\mathrm{a})$ and $4(\mathrm{~b}))$. However, at $16 \mathrm{hr}$ after challenge, the bacterial CFUs from CFA/I-immunized mice were significantly less than sPBS-dosed mice in spleen, liver, and kidneys by 27.9fold $(P<0.05)$, 4.3 -fold $(P<0.05)$, and 11.1 -fold $(P<$ 0.01 ), respectively (Figure $4(\mathrm{c})$ ). Although the lungs showed no significant differences, the bacterial CFUs appeared to be diminished in the CFA/I-immunized mice relative to sPBS controls. These results suggest the ETEC replication in the immunized mice is reduced following CFA/I fimbrial immunization.

3.7. Evaluation of the Bactericidal Activity of the CFA/I Fimbriae-Immunized Mouse Sera. Since the serum IgG titers correlate to protective immunity, we questioned whether 


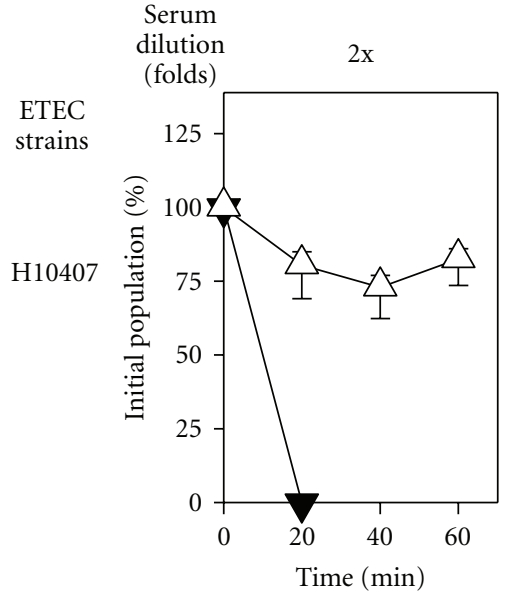

(a)

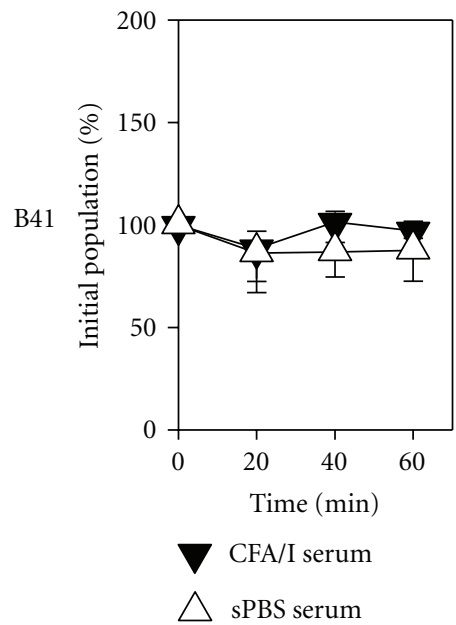

(e)

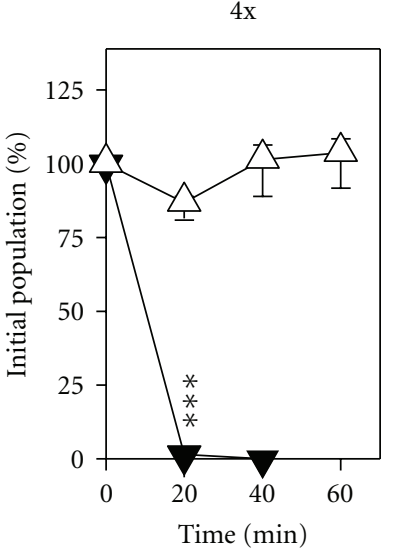

(b)

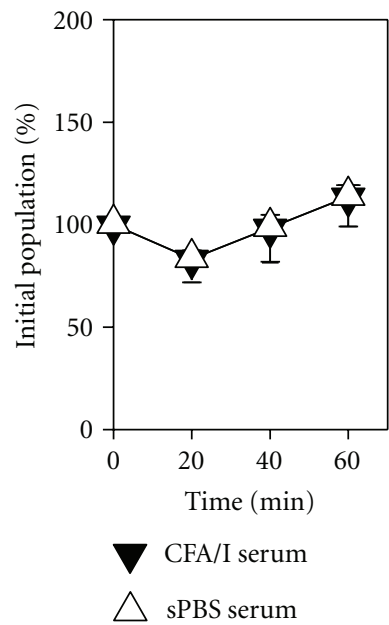

(f)

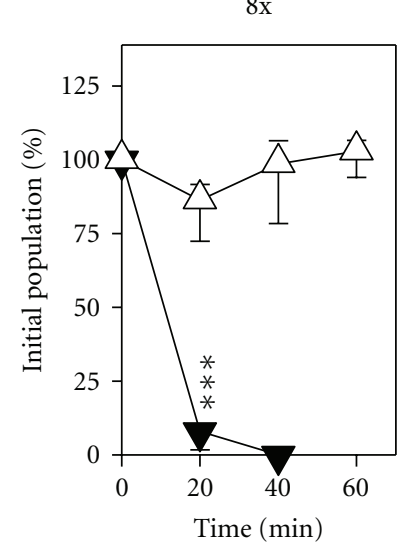

(c)

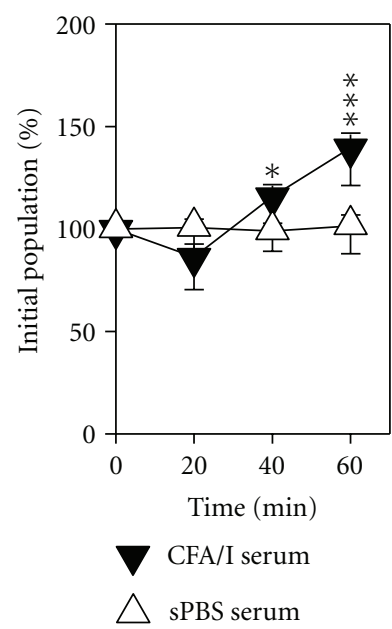

(g)

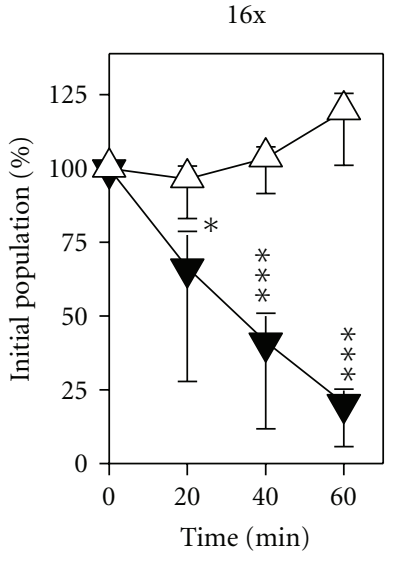

(d)

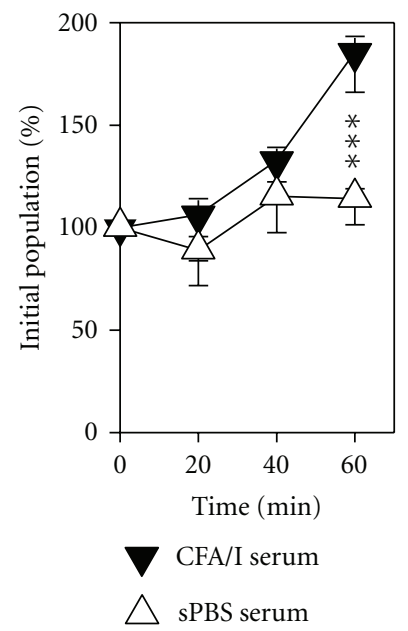

(h)

FIGURE 5: The sera from the CFA/I-immunized mice are effective in killing wt CFA/I ${ }^{+}$ETEC H10407 but not K99 ${ }^{+}$ETEC B41. The sera of the $60 \mu \mathrm{g}$ CFA/I-immunized mice were compared to those from sPBS-dosed mice (Figure 1) for bactericidal activity serially diluted (a, e) 2-, (b, f) 4-, (c, g) 8-, and (d, h) 16-fold. Depicted are the percentages of the survival bacterial CFU relevant to the initial bacterial CFU before supplement of sera (time $=0 \mathrm{~min}$ ). At 20,40, and $60 \mathrm{~min}$ after incubation, the bacterial survival rates were statistically calculated between anti-CFA/I sera and the -sPBS sera via Student's $t$-test: ${ }^{*} P<0.05,{ }^{* *} P<0.01$, and ${ }^{* * *} P<0.001$. Values are the mean \pm SEM $(n=3)$.

protection conferred by the CFA/I fimbriae was due to the bactericidal effects from the sera. The sera from the $60 \mu \mathrm{g}$ CFA/I fimbriae-immunized mice were assessed for the bactericidal activity with the sPBS-dosed mouse sera as the control (Figure 1). The results showed that sera from the sPBS-dosed mice displayed no bactericidal effect to H10407 (Figures 5(a)-5(d)). However, 2-fold dilution of the anti-CFA/I sera killed all H10407 ETEC within $20 \mathrm{~min}$ (Figure 5(a)); at 4- and 8-fold dilution, they were all killed within $40 \mathrm{~min}$ (Figures 5(b) and 5(c)); and at 16 -fold dilution, $79.5 \%$ of the bacteria was killed within 60 min (Figure 5(d)). These results clearly indicate that the anti-CFA/I sera are highly effective in killing homologous bacteria, confirming the observation that CFA/I-immunized mice were protected from wt ETEC challenge.

To determine whether the anti-CFA/I sera were able to neutralize the heterologous ETEC pathogen B41, a B41 bactericidal assay was performed, similar to the H10407 bactericidal assay. The results showed that the anti-CFA/I sera were ineffective in killing B41 (Figures 5(e)-5(h)). At 2- and 4-fold dilutions, B41 CFUs showed no differences between anti-CFA/I sera and control sera treatment at any time points (Figures 5(e) and 5(f)). For the 8- and 16fold dilutions, the anti-CFA/I sera seemed to stimulate the reproduction of B41 since its CFUs were significantly increased when compared to control sera treatment for 40 60 min after incubation (Figures $5(\mathrm{~g})$ and $5(\mathrm{~h})$ ). These results show that anti-CFA/I sera are not effective for neutralizing K99+ ETEC.

\section{Discussion}

Although a previous study had shown that human ETEC $\mathrm{H} 10407$ is lethal to BALB/c mice when given nasally at the dose of $7 \times 10^{8}$ CFUs [27], in our study, nasally administered H10407 was not lethal to BALB/c mice. Increasing 
the infection dose by one log resulted in only $50 \%$ lethality, and no protective effect was conferred upon oral vaccination (Figure 3(d)). Similarly, oral challenge was ineffective, since H10407 was not lethal (Figure 3(c)). Alternatively, mice were highly sensitive to ETEC when challenged i.p. (Figure 3(e)). It remains unclear why i.n. ETEC infection was ineffective, while i.p. challenge allowed evaluation of protective Abs to ETEC, especially antifimbrial Abs. As shown, oral immunization with a Salmonella vaccine expressing CFA/I fimbriae elicited elevated serum and mucosal Abs capable of conferring protection against i.p. ETEC challenge. This result was similar to the previous observation that mice are sensitive to swine ETEC via i.p., which is able to distinguish the immunized from the nonimmunized control [29]. Since Salmonella does disseminate systemically [4], it readily immunizes systemically, eliciting elevated Ag-specific Abs, as evidenced here. Our study shows that parenterally induced antifimbrial Abs are protective, similar to those which had been shown in the case of rabbits $[32,33]$.

A limitation of fimbrial proteins for oral immunization is its lack of efficacy $[48,49]$ presumably attributed to its denaturation in the GI tract [50]. Aside from problems associated with live vaccines or the limitations of oral immunization with killed ETEC [51], one possible alternative for protection of newborns is via passive immunity, which has been proven effective $[31,33,52]$. To this end, studies were conducted using low-endotoxin CFA/I fimbriae to assess whether i.m. immunization would be effective to stimulate antifimbrial Abs. Interestingly, i.m. immunization with the recombinant CFA/I fimbriae was found to stimulate elevated serum IgG and mucosal IgA Abs in the absence of adjuvant. In fact, as little as $60 \mu \mathrm{g}$, given twice, was sufficient to confer complete protection against i.p. ETEC challenge. Moreover, as little as a single dose with $30 \mu \mathrm{g}$ was sufficient to confer $88 \%$ protection. Coadministration of CT adjuvant was able to provide $100 \%$ protection achieved with a single dose of $10 \mu \mathrm{g}$ CFA/I. Less efficacious, the oral Salmonella vaccine elicited $80 \%$ protection, implicating the possible advantage of parenteral booster immunizations. Further studies using sera from CFA/I fimbriae-immunized mice exhibited robust bactericidal activity against wt ETEC H10407 since after 16fold dilution it was still able to kill nearly all bacteria within $1 \mathrm{hr}$. These findings clearly indicate that CFA/I fimbriae are effective immunogens for stimulating protective immunity, suggesting that booster immunizations with purified ETEC fimbriae could be given to pregnant mothers to ensure stimulation of protective Abs. For ETEC vaccines, there may be some strain (fimbriae) specificity since the anti-CFA/I sera did not show any bactericidal activity against K99+ ETEC, strain B41. Although other ETEC strains may be sensitive to the enhanced CFA/I bactericidal activity, these results imply Ag specificity for optimal impact.

Serum IgG subclass responses revealed that immunization with detoxed CFA/I fimbriae favored an IgG1 (Th2type) immune response, as opposed to the live Salmonella vaccine that induced both IgG1 and IgG2a Abs, suggesting that a mixed Th1 and Th2 phenotype was induced. In the absence of CFA/I fimbriae, the Salmonella vaccine vector normally stimulates a Th1 cell response [16]. Although the protective efficacy of anti-Salmonella infection was not evaluated, we have previously shown that our Salmonellabased ETEC vaccines are protective against wt Salmonella infections [53]. An effective bivalent vaccine for both ETEC and salmonellosis would assist in control of these two relevant human diarrheal pathogens.

In summary, this study shows that parenteral immunization with purified CFA/I fimbriae potently induces serum IgG Abs in the absence of adjuvant. With adjuvant, singledose immunization was achieved and proven effective against i.p. challenge with ETEC. Since there is not currently a vaccine for ETEC that can afford sustained and broadbased protection [51], exploring alternative immunization regimens, as described here or coupled with transcutaneous immunization methods [54], may provide some helpful benefits. Alternatively, additional universal protective Ags may be necessary, as suggested by others [55].

\section{Conflict of Interests}

The authors declare no conflict of interests.

\section{Acknowledgments}

The authors thank Ms. Nancy Kommers for her assistance in preparing this paper. This work was supported by National Institutes of Health Grants nos. R21 AI-080960, R01 AI41123, and P20 RR020185, an equipment grant from the M. J. Murdock Charitable Trust, the Montana Agricultural Station, and U.S. Department of Agriculture Formula Funds. It is also supported in part by Office of Navy Research Award N00014-10-1-0946.

\section{References}

[1] H. L. DuPont, "New insights and directions in travelers' diarrhea," Gastroenterology Clinics of North America, vol. 35, no. 2, pp. 337-353, 2006.

[2] H. L. DuPont and Z. D. Jiang, "Influence of rifaximin treatment on the susceptibility of intestinal Gram-negative flora and enterococci," Clinical Microbiology and Infection, vol. 10, no. 11, pp. 1009-1011, 2004.

[3] J. Ouyang-Latimer, S. Jafri, A. Vantassel et al., "In vitro antimicrobial susceptibility of bacterial enteropathogens isolated from international travelers to Mexico, Guatemala, and India, 2006-2008," Antimicrobial Agents Chemotherapy, vol. 55, pp. 874-878, 2011.

[4] Z. D. Jiang, H. L. Dupont, E. L. Brown et al., "Microbial etiology of travelers' diarrhea in Mexico, Guatemala, and India: importance of enterotoxigenic Bacteroides fragilis and Arcobacter species," Journal of Clinical Microbiology, vol. 48, no. 4, pp. 1417-1419, 2010.

[5] J. W. Sahl, H. Steinsland, J. C. Redman et al., "A comparative genomic analysis of diverse clonal types of enterotoxigenic Escherichia coli reveals pathovar-specific conservation," Infection and Immunity, vol. 79, no. 2, pp. 950-960, 2011.

[6] C. Wennerås and V. Erling, "Prevalence of enterotoxigenic Escherichia coli-associated diarrhoea and carrier state in the developing world," Journal of Health, Population and Nutrition, vol. 22, no. 4, pp. 370-382, 2004. 
[7] M. E. Beatty, P. M. Adcock, S. W. Smith et al., "Epidemic diarrhea due to enterotoxigenic Escherichia coli," Clinical Infectious Diseases, vol. 42, no. 3, pp. 329-334, 2006.

[8] J. P. Nataro and J. B. Kaper, "Diarrheagenic Escherichia coli," Clinical Microbiology Reviews, vol. 11, no. 1, pp. 142-201, 1998.

[9] B. Nagy and P. Z. Fekete, "Enterotoxigenic Escherichia coli (ETEC) in farm animals," Veterinary Research, vol. 30, no. 2-3, pp. 259-284, 1999.

[10] E. M. Barry, Z. Altboum, G. Losonsky, and M. M. Levine, "Immune responses elicited against multiple enterotoxigenic Escherichia coli fimbriae and mutant LT expressed in attenuated Shigella vaccine strains," Vaccine, vol. 21, no. 5-6, pp. 333-340, 2003.

[11] J. M. Fleckenstein, P. R. Hardwidge, G. P. Munson, D. A. Rasko, H. Sommerfelt, and H. Steinsland, "Molecular mechanisms of enterotoxigenic Escherichia coli infection," Microbes and Infection, vol. 12, no. 2, pp. 89-98, 2010.

[12] S. M. Turner, A. Scott-Tucker, L. M. Cooper, and I. R. Henderson, "Weapons of mass destruction: virulence factors of the global killer enterotoxigenic Escherichia coli," FEMS Microbiology Letters, vol. 263, no. 1, pp. 10-20, 2006.

[13] F. J. Cassels and M. K. Wolf, "Colonization factors of diarrheagenic E. coli and their intestinal receptors," Journal of Industrial Microbiology, vol. 15, no. 3, pp. 214-226, 1995.

[14] D. G. Evans, D. J. Evans Jr., A. R. Opekun, and D. Y. Graham, "Non-replicating oral whole cell vaccine protective against enterotoxigenic Escherichia coli (ETEC) diarrhea: stimulation of anti-CFA (CFA/I) and anti-enterotoxin (anti-LT) intestinal IgA and protection against challenge with ETEC belonging to heterologous serotypes," FEMS Microbiology Immunology, vol. 47, no. 3, pp. 117-125, 1988.

[15] A. M. Svennerholm, J. Holmgren, and D. A. Sack, "Development of oral vaccines against enterotoxinogenic Escherichia coli diarrhoea," Vaccine, vol. 7, no. 3, pp. 196-198, 1989.

[16] D. W. Pascual, D. M. Hone, S. Hall et al., "Expression of recombinant enterotoxigenic Escherichia coli colonization factor antigen I by Salmonella typhimurium elicits a biphasic $\mathrm{T}$ helper cell response," Infection and Immunity, vol. 67, no. 12, pp. 6249-6256, 1999.

[17] N. Walters, T. Trunkle, M. Sura, and D. W. Pascual, "Enhanced immunoglobulin A response and protection against Salmonella enterica serovar Typhimurium in the absence of the substance P receptor," Infection and Immunity, vol. 73, no. 1, pp. 317-324, 2005.

[18] W. Gaastra and F. K. de Graaf, "Host-specific fimbrial adhesins of noninvasive enterotoxigenic Escherichia coli strains," Microbiological Reviews, vol. 46, no. 2, pp. 129-161, 1982.

[19] G. W. Jones and J. M. Rutter, "Role of the K88 antigen in the pathogenesis of neonatal diarrhea caused by Escherichia coli in piglets," Infection and Immunity, vol. 6, no. 6, pp. 918-927, 1972.

[20] J. L. Kiers, M. J. R. Nout, F. M. Rombouts, M. J. A. Nabuurs, and J. van der Meulen, "Inhibition of adhesion of enterotoxigenic Escherichia coli K88 by soya bean tempe," Letters in Applied Microbiology, vol. 35, no. 4, pp. 311-315, 2002.

[21] L. L. Myers and P. A. Guinee, "Occurrence and characteristics of enterotoxigenic Escherichia coli isolated from calves with diarrhea," Infection and Immunity, vol. 13, no. 4, pp. 1117$1119,1976$.

[22] I. Orskov, F. Orskov, H. Williams Smith, and W. J. Sojka, "The establishment of K99, a thermolabile, transmissible Escherichia coli $\mathrm{K}$ antigen, previously called "Kco" possessed by calf and lamb enteropathogenic strains," Acta Pathologica et Microbiologica Scandinavica-Section B Microbiology and Immunology, vol. 83, no. 1, pp. 31-36, 1975.

[23] H. W. Moon, B. Nagy, R. E. Isaacson, and I. Orskov, "Occurrence of K99 antigen on Escherichia coli isolated from pigs and colonization of pig ileum by $\mathrm{K} 99^{+}$enterotoxigenic $E$. coli from calves and pigs," Infection and Immunity, vol. 15, no. 2, pp. 614-620, 1977.

[24] D. G. Evans, D. J. Evans Jr., and H. L. DuPont, "Virulence factors of enterotoxigenic Escherichia coli," Journal of Infectious Diseases, vol. 136, no. 2, pp. S118-S123, 1977.

[25] D. G. Evans, D. J. Evans Jr., W. S. Tjoa, and H. L. DuPont, "Detection and characterization of colonization factor of enterotoxigenic Escherichia coli isolated from adults with diarrhea," Infection and Immunity, vol. 19, no. 2, pp. 727-736, 1978.

[26] R. W. Ryder, I. K. Wachsmuth, and A. E. Buxton, "Infantile diarrhea produced by heat stable enterotoxigenic Escherichia coli," New England Journal of Medicine, vol. 295, no. 16, pp. 849-853, 1976.

[27] W. Byrd and F. J. Cassels, "Mucosal immunization of BALB/c mice using enterotoxigenic Escherichia coli colonization factors CFA/I and CS6 administered with and without a mutant heat-labile enterotoxin," Vaccine, vol. 21, no. 17-18, pp. 1884$1893,2003$.

[28] J. K. Liu, X. L. Hou, C. H. Wei et al., "Induction of immune responses in mice after oral immunization with recombinant Lactobacillus casei strains expressing enterotoxigenic Escherichia coli F41 fimbrial protein," Applied and Environmental Microbiology, vol. 75, no. 13, pp. 4491-4497, 2009.

[29] J. You, Y. Xu, M. He et al., "Protection of mice against enterotoxigenic $E$. coli by immunization with a polyvalent enterotoxin comprising a combination of LTB, STa, and STb," Applied Microbiology and Biotechnology, vol. 89, pp. 18851893, 2011.

[30] C. H. Wei, J. K. Liu, X. L. Hou, L. Y. Yu, J. S. Lee, and C. J. Kim, "Immunogenicity and protective efficacy of orally or intranasally administered recombinant Lactobacillus casei expressing ETEC K99," Vaccine, vol. 28, no. 24, pp. 4113-4118, 2010.

[31] M. A. Ascón, D. M. Hone, N. Walters, and D. W. Pascual, "Oral immunization with a Salmonella typhimurium vaccine vector expressing recombinant enterotoxigenic Escherichia coli K99 fimbriae elicits elevated antibody titers for protective immunity," Infection and Immunity, vol. 66, no. 11, pp. 54705476, 1998.

[32] A. M. Svennerholm, C. Wenneras, J. Holmgren, M. M. McConnell, and B. Rowe, "Roles of different coli surface antigens of colonization factor antigen II in colonization by and protective immunogenicity of enterotoxigenic Escherichia coli in rabbits," Infection and Immunity, vol. 58, no. 2, pp. 341346, 1990.

[33] C. O’Farrelly, D. Branton, and C. A. Wanke, "Oral ingestion of egg yolk immunoglobulin from hens immunized with an enterotoxigenic Escherichia coli strain prevents diarrhea in rabbits challenged with the same strain," Infection and Immunity, vol. 60, no. 7, pp. 2593-2597, 1992.

[34] D. J. Freedman, C. O. Tacket, A. Delehanty, D. R. Maneval, J. Nataro, and J. H. Crabb, "Milk immunoglobulin with specific activity against purified colonization factor antigens can protect against oral challenge with enterotoxigenic Escherichia coli," Journal of Infectious Diseases, vol. 177, no. 3, pp. 662-667, 1998. 
[35] M. F. Mian, E. A. Pek, M. J. Chenoweth, and A. A. Ashkar, "Humanized mice are susceptible to Salmonella typhi infection," Cellular and Molecular Immunology, vol. 8, no. 1, pp. 83-87, 2011.

[36] S. Wu, D. W. Pascual, J. L. Vancott et al., "Immune responses to novel Escherichia coli and Salmonella typhimurium vectors that express colonization factor antigen I (CFA/I) of enterotoxigenic E. coli in the Absence of the CFA/I positive regulator cfaR," Infection and Immunity, vol. 63, no. 12, pp. 4933-4938, 1995.

[37] D. J. Evans and D. G. Evans, "Three characteristics associated with enterotoxigenic Escherichia coli isolated from man," Infection and Immunity, vol. 8, no. 3, pp. 322-328, 1973.

[38] M. A. Ascón, D. M. Hone, N. Walters, and D. W. Pascual, "Oral immunization with a Salmonella typhimurium vaccine vector expressing recombinant enterotoxigenic Escherichia coli K99 fimbriae elicits elevated antibody titers for protective immunity," Infection and Immunity, vol. 66, no. 11, pp. 54705476, 1998.

[39] L. C. Crossman, R. R. Chaudhuri, S. A. Beatson et al., "A commensal gone bad: complete genome sequence of the prototypical enterotoxigenic Escherichia coli strain H10407," Journal of Bacteriology, vol. 192, no. 21, pp. 5822-5831, 2010.

[40] H. L. Bullifent, K. F. Griffin, S. M. Jones, A. Yates, L. Harrington, and R. W. Titball, "Antibody responses to Yersinia pestis F1-antigen expressed in Salmonella typhimurium aroA from in vivo-inducible promoters," Vaccine, vol. 18, no. 24, pp. 2668-2676, 2000.

[41] X. Yang, B. J. Hinnebusch, T. Trunkle et al., "Oral vaccination with Salmonella simultaneously expressing Yersinia pestis F1 and $\mathrm{V}$ antigens protects against bubonic and pneumonic plague," Journal of Immunology, vol. 178, no. 2, pp. 1059-1067, 2007.

[42] R. H. Hall, D. R. Maneval Jr., J. H. Collins, J. L. Theibert, and M. M. Levine, "Purification and analysis of colonization factor antigen I, coli surface antigen 1, and coli surface antigen 3 fimbriae from enterotoxigenic Escherichia coli," Journal of Bacteriology, vol. 171, no. 11, pp. 6372-6374, 1989.

[43] M. E. North, C. A. Newton, D. J. Wright, and A. D. Webster, "Bactericidal activity of serum for Klebsiella rhinoscleromatis: studies on serum from a patient with rhinoscleroma and sera deficient in antibody or complement," Journal of Medical Microbiology, vol. 15, no. 2, pp. 267-272, 1982.

[44] J. P. Allison, "Recent advances in mucosal vaccines and adjuvants," Current Opinion in Immunology, vol. 14, no. 5, pp. 666-672, 2002.

[45] J. M. Taylor, M. E. Ziman, D. R. Canfield, M. Vajdy, and J. V. Solnick, "Effects of a Th1- versus a Th2-biased immune response in protection against Helicobacter pylori challenge in mice," Microbial Pathogenesis, vol. 44, no. 1, pp. 20-27, 2008.

[46] S. L. Reiner, "Development in motion: helper T cells at work," Cell, vol. 129, no. 1, pp. 33-36, 2007.

[47] D. J. Asper, J. Gawaziuk, A. A. Potter, and V. Gerdts, "Rallying the troops: innate mucosal responses to enteric pathogens," Current Immunology Reviews, vol. 5, no. 4, pp. 249-266, 2009.

[48] R. Edelman, R. G. Russell, G. Losonsky et al., "Immunization of rabbits with enterotoxigenic E. coli colonization factor antigen (CFA/I) encapsulated in biodegradable microspheres of poly (lactide-co-glycolide)," Vaccine, vol. 11, no. 2, pp. 155$158,1993$.

[49] D. G. Evans, D. Y. Graham, and D. J. Evans Jr., "Administration of purified colonization factor antigens (CFA/I, CFA/II) of enterotoxigenic Escherichia coli to volunteers," Gastroenterology, vol. 87, no. 4, pp. 934-940, 1984.
[50] M. Schmidt, E. P. Kelly, L. Y. Tseng, and E. C. Boedeker, "Towards an oral E. coli pilus vaccine for travelers diarrhea: susceptibility to proteolytic digestion," Gastroenterology, vol. 88, pp. A1575-A1582, 1985.

[51] E. C. Boedeker, "Vaccines for enterotoxigenic Escherichia coli: current status," Current Opinion in Gastroenterology, vol. 21, no. 1, pp. 15-19, 2005.

[52] D. R. Snodgrass, L. K. Nagy, D. Sherwood, and I. Campbell, "Passive immunity in calf diarrhea: vaccination with K99 antigen of enterotoxigenic Escherichia coli and rotavirus," Infection and Immunity, vol. 37, no. 2, pp. 586-591, 1982.

[53] D. W. Pascual, M. D. White, T. Larson, and N. Walters, "Impaired mucosal immunity in L-selectin-deficient mice orally immunized with a Salmonella vaccine vector," Journal of Immunology, vol. 167, no. 1, pp. 407-415, 2001.

[54] J. Yu, F. Cassels, T. Scharton-Kersten et al., "Transcutaneous immunization using colonization factor and heat-labile enterotoxin induces correlates of protective immunity for enterotoxigenic Escherichia coli," Infection and Immunity, vol. 70, no. 3, pp. 1056-1068, 2002.

[55] K. Roy, S. Bartels, F. Qadri, and J. M. Fleckenstein, "Enterotoxigenic Escherichia coli elicits immune responses to multiple surface proteins," Infection and Immunity, vol. 78, no. 7, pp. 3027-3035, 2010. 


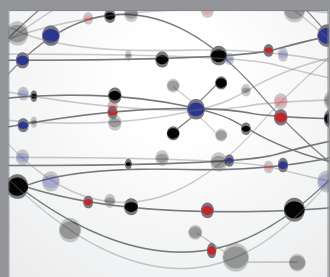

The Scientific World Journal
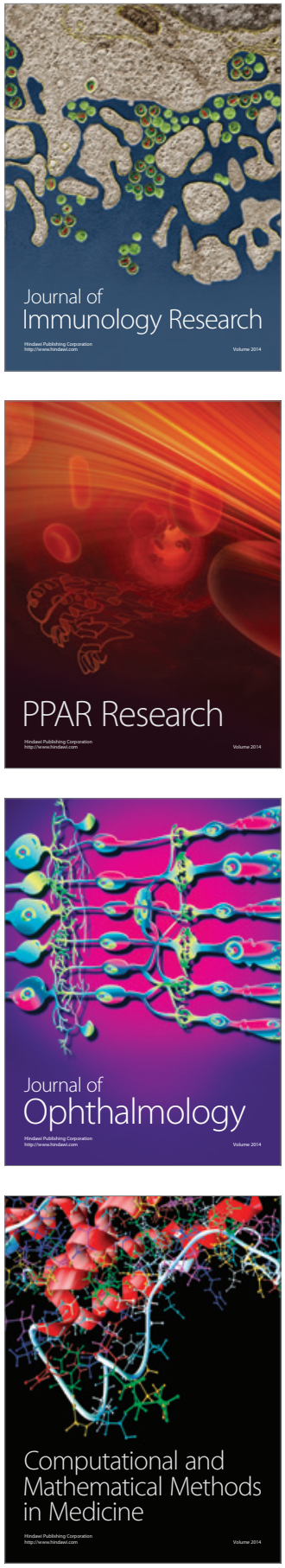

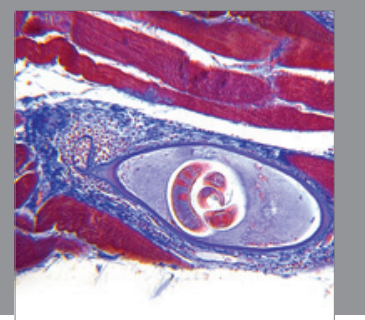

Gastroenterology

Research and Practice
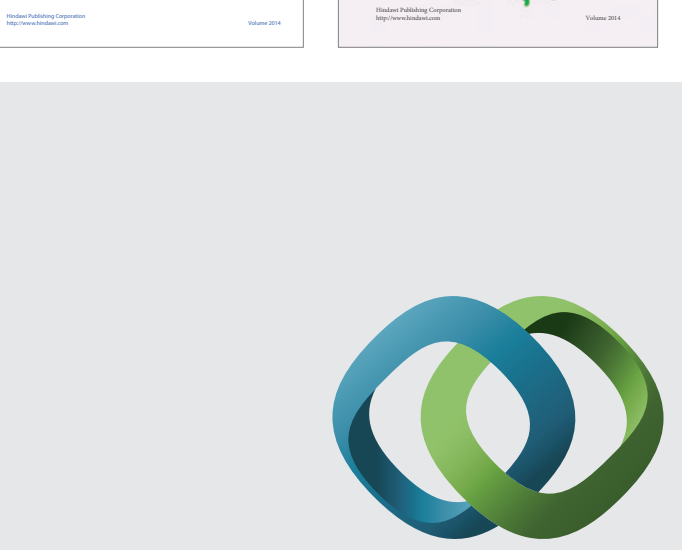

\section{Hindawi}

Submit your manuscripts at

http://www.hindawi.com
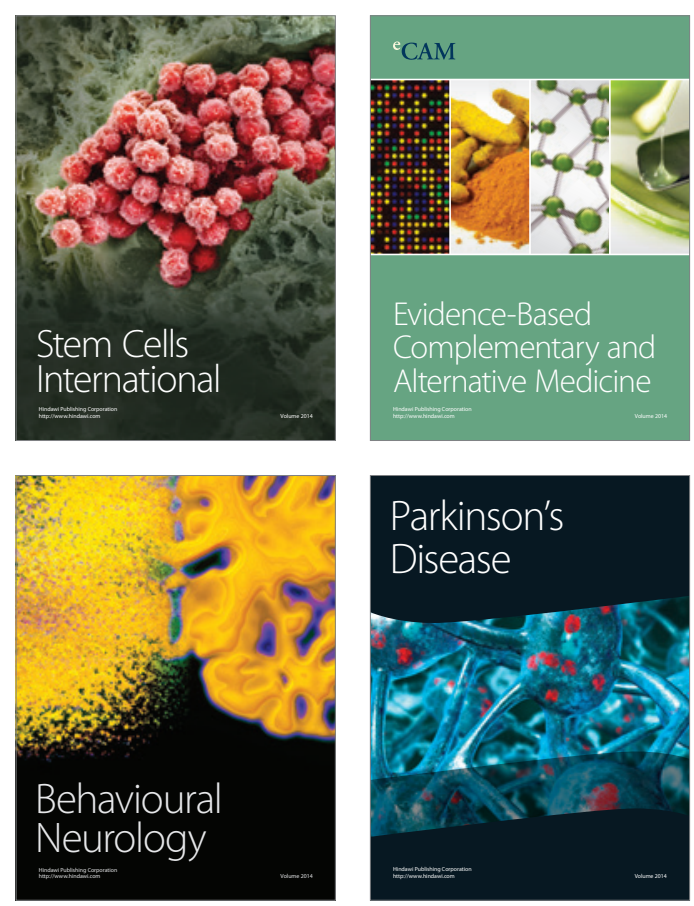

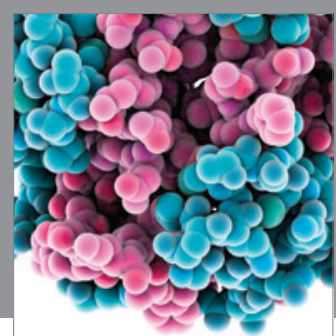

Journal of
Diabetes Research

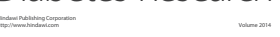

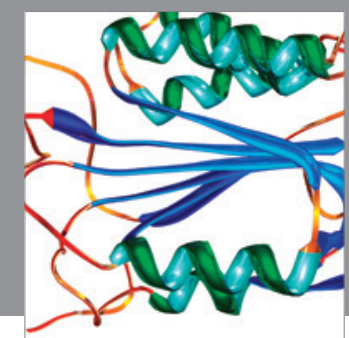

Disease Markers
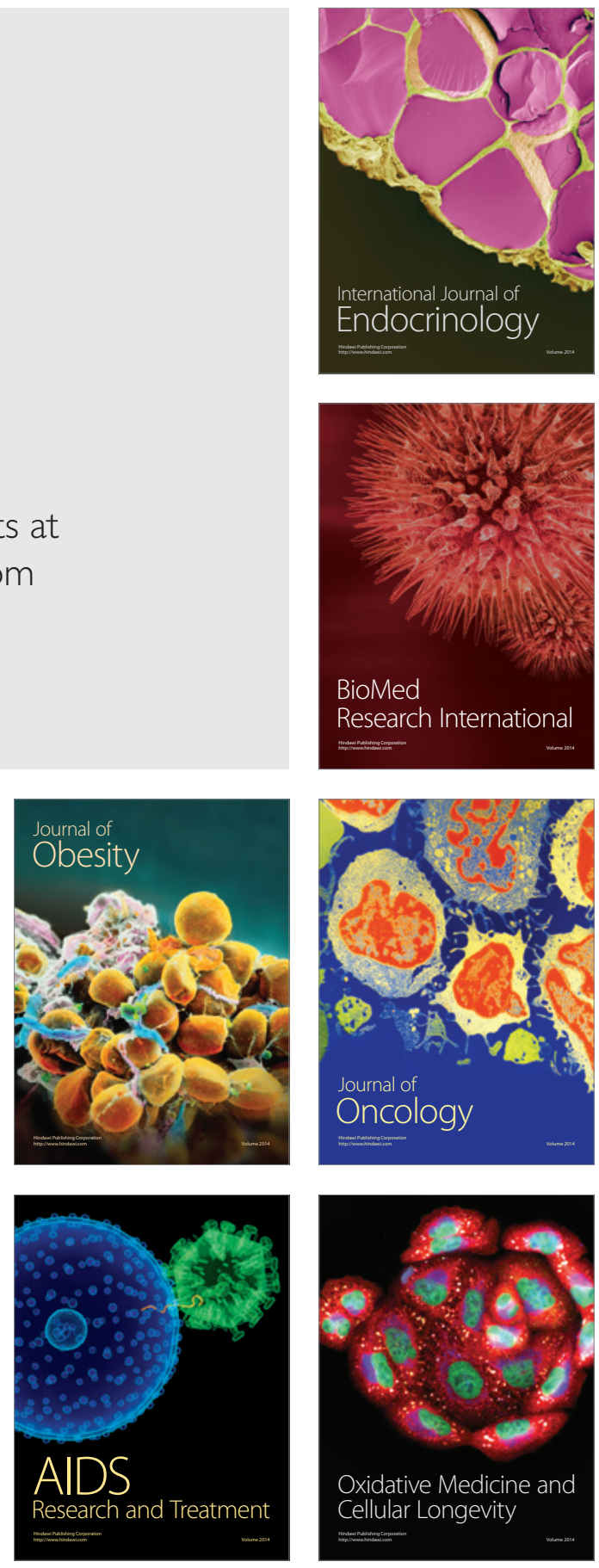